\title{
Bernard iz Clairvauxa: Dva govora
}

\author{
Prevedla Breda Čop
}

$\mathrm{Na}$ 12. stoletje je s svojim duhovnim in kulturnim delovanjem tako izredno vplival sv. Bernard, da ta čas smemo poimenovati kar Bernardovo stoletje. Velike in vsestransko pomembne osebnosti tega svetnika pa ni mogoče predstaviti z enim samim imenom oziroma nazivom.

Poznamo ga kot ustanovitelja cistercijanskega reda: čeprav je vstopil vanj, ko je bil red že ustanovljen, je ob njegovem prihodu na novo zaživel in se močno razvil. Red je iz skromnih začetkov prerasel v mogočno ustanovo, ki je obsegala že mnogo samostanov in v času sv. Bernarda doživela duhovni, kulturni in gospodarski razcvet. Sv. Bernard je cistercijane in njihovo pravilo (Charta Caritatis) tako odločilno prenovil in toliko prispeval k organizaciji in širjenju reda, da je prevzel mesto prvotnega ustanovitelja sv. Roberta.

Od otroških let dalje se je z veliko vnemo poglabljal v Sveto pismo, poznal ga je tako dobro, da je zlahka vse svoje misli izražal v svetopisemskem jeziku. Nič manj ni obvladal velike teologije cerkvenih očetov, popolnoma jo je osvojil in bil je dobesedno prepojen z njihovo mislijo, postal je tako rekoč eden od njih, zato je obveljal za najodličnejšega predstavnika »srednjeveške patristike» in zadnjega med cerkvenimi očeti.

Iz premišljevanja Svetega pisma in cerkvenih očetov je nastalo mnogo del, ki so bila več stoletij pravo vzgojno in izobraževalno branje. Papež Pij VIII. mu je priznal izjemno učiteljstvo in veliko svetništvo in ga povzdignil med cerkvene učitelje. Papež Benedikt XVI. pravi, da je njegova knjiga De consideratione "primerno branje za papeže vseh časov«, in ga imenuje "učitelj papežev«.

Bernard poudarja, da je samo Jezus "mel in ore, in aure melos, in corde iubilum ", in prav na podlagi tega znamenitega stavka je nastalo ime, ki mu ga je nadelo izročilo: doctor mellifluus. Tako neustavljivo privlačna in ljubezniva je bila namreč njegova govorica, da je »tekla kakor med «.

Bernardova literarna zapuščina ni posebno obširna, napisal je precej manj 
kakor njegovi sodobniki, in vendar je doživel velikanski uspeh: njegova dela so prepisovali, tiskali, kopirali, povsod in neutrudljivo in v vseh časih. Preizkusil se je v mnogih literarnih zvrsteh: v satiri, v govorih, v mislih, v razpravah, $\mathrm{v}$ svetopisemskih komentarjih; pisal je od najnežnejše mladosti do zadnjega dne, do smrti.

Najobsežnejše delo bi lahko naslovili kar »Liturgično leto«: dolga vrsta govorov komentira skrivnosti odrešenja in besedila, ki te skrivnosti napovedujejo. V zadnjih letih življenja je natančno pregledal vse svoje govore, jih dopolnil in razvrstil tako, da so iz njih nastale razprave o posameznih delih bogoslužnega leta: o adventnem, o božičnem, o postnem, o velikonočnem času in o času med letom.

Besedilv obliki govorov, ki jih je nato izdal, ni govoril; namige na okoliščine ali poslušalce vsebujejo zato, ker je tako predpisovala literarna zvrst. Besedišče je največkrat svetopisemsko: Sveto pismo velikokrat navaja v različici, ki jo je našel pri cerkvenih očetih ali pa jo je bral oziroma slišal pri cerkvenih obredih. Nenehno je prebiral in premišljeval patristične tekste, misel cerkvenih očetov ga je popolnoma prevzela, tako da je iz nje potegnil več, kakor je hotel povedati avtor sam; postala je njegova.

K svetopisemskim navedkom dodaja liturgične reminiscence. Če govori o skrivnosti, ki se je spominjamo na neki praznik, je vedno bogoslužje tisto, ki usmerja razlago. Veliko število svetopisemskih navedkov je podlaga govora, liturgija pa ustvari ozračje in celoti daje barvitost. Vsi ti odtenki svetopisemske in bogoslužne latinščine, pa tudi besedni zaklad, ki mu daje močan pečat samostanski jezik, se v prevodu nujno izgubijo. Nemogoče je v slovenščini izraziti vso melodičnost in zvočne učinke, vse besedne igre, aliteracije, rime in ubranost vsakega stavka posebej. Njegovi teksti naravnost kličejo po tem, da jih razčlenimo in preiskujemo, ne samo prebiramo.

Bernard, tradicionalen in patrističen, kakor je, je istočasno povsem srednjeveški. Lahko bi rekli: še več, za vse čase je, ob branju njegovih del je namreč izpolnjena najbolj univerzalna človekova potreba, dvigniti se nad samega sebe, da bi se povezal z Lepoto, ki ga presega. 


\section{O TREH VEZEH: VRVEH, ŽEBLJIH, LEPILU}

Ta govor, ki sodi med Govore za različne priložnosti, se začenja z najemom: kakor v svetopisemski priliki (Mt 20.6-7) Oče najame delavce, tukaj najame iskalce Boga. Bog prihaja knam, $v$ zameno pa ga mi čakamo in iščemo. Iskanje Boga zagotavlja vstop v slavo; tisti namreč, ki je iskan, je v nekem smislu že najden. Nasprotno pa se tisti, ki ne išče, prostovoljno odpove sreči; sreča je v tem, da bi ga našel. Tri vezi nas vežejo z Bogom: vrvi (čast), žeblji (strah pred peklom) in lepilo (ljubezen do Boga). V trpljenju je bil tudi Kristus zvezan, z žeblji je bil pribit na križ. Bernard torej pokaže, kako iskalci Boga hodijo za Kristusom in za njim tudi sami vstopijo v slavo.

1. Tukaj ne postajamo ves dan brez dela (Mt 20.6). Vemo namreč, kaj iščemo in kdo je, ki nas je najel (Mt 20.7). Boga iščemo, Boga čakamo (Mih 7.7). ${ }^{1}$ To ni majhna zadeva, pa tudi ne za malodušnega človeka, kajti ta, ki se ponaša $\mathrm{z}$ edinstvenim ljubkovalnim imenom, se pritožuje, da je bila prepogosto razočarana. ${ }^{2}$ Iskala sem ga, pravi, pa ga nisem našla (Vp 3.2). Ljubezniv je namreč, hkrati pa tudi občudovanja vreden, se pravi: takrat, ko ga ne iščemo, ga najdemo, ne najdemo pa ga, kadar ga iščemo (prim. Iz 65.1). Tudi če bi se rodili, ko je bil ustvarjen človek na zemlji, in bi se naše življenje razvleklo na sto tisoč let, iskanja sedanjega časa vendarle ne bi bilo mogoče primerjati s slavo, ki se bo razodela $v$ nas (Rim 8.18 ).

Glejte, zdaj je čas iskanja, glejte, zdaj so, na dosegu rok, dnevi (2 Kor 6.2), ko ga lahko najdemo: Iščite Gospoda, pravi, dokler se daje najti, kličite ga, dokler je blizu! (Iz 55.6). Prišel bo čas, ko ne bo več možnosti, ker bo oni studenec usmiljenja presahnil v neminljivi suhoti. Iskali me boste, pravi, in me ne boste našli (Jn 7.34).

Dober si, Gospod, duši, ki te išče (Žal 3.25). Če si dober duši, ki te išče, koliko bolj tisti, ki te najde? Če je že samo misel nate tako sladka, kakšna bo navzočnost? Če sta med in mleko pod tvojim jezikom (Vp 4.11) tako sladka, kakšna bosta šele na jeziku?

2. Ob tem preverite, bratje, ali ste na poti ali ste z nje zašli. Naj se veseli, pravi, srce tistih, ki iščejo Gospoda (Ps 104.3). ${ }^{3}$ Če se veselite v naporih, če z neovirano in neutrudljivo nogo tečete po poti božjih zapovedi (Ps 118.32), če se stanje notranjega in zunanjega človeka vsak dan približuje bolj napredovanju in izpopolnjevanju kakor začenjanju, potem zagotovo iščete njegovo obličje (Ps 104.4). ${ }^{4}$

Kam je šel ljubi pred drugimi ljubimi, da ga bomo iskale? (Vp 5.17; 5.9) Kje je

1 Sreča, da iščemo Boga, je samo uvod v srečo, ki jo dosežemo, ko ga najdemo.

2 Bernard pokaže na nevesto iz Visoke pesmi, ki je hkrati podoba Cerkve in duše. Predmet pričakovanja je Kristus, ki bo iskalcem Boga odprl vstop v slavo, kakor bo potrdil sklepni del tega govora.

3 Bog je vsepovsod, ljudje, ki jih teži izvirni greh, pa ga morajo zaradi svoje odtujitve (izvirnega greha) najprej najti.

4 Skrb za napredovanje vsak dan posebej je bila vodilna misel sv. Antona, očeta puščavnikov. 
zdaj? Kaj sem rekel, nesrečnež? Pravzaprav, kje ga ni? Višji je od neba, globlji od pekla, bolj prostran kakor zemlja, bolj brezmejen kakor morje. Nikjer ga ni, in povsod je, ker ni kraja, kjer ga ni, in ni kraja, kjer je.

On je tukaj (Mt 24.23), ampak mene ni tukaj. ${ }^{5}$ Koliko bolj verjetno bi se zdelo, če tebe ne bi bilo tukaj in bi bil jaz tukaj, Gospod! Toda mene ni ne tukaj ne drugje, ker sem bil priveden do niča, in nisem vedel (Ps 72.22). Prav zares, do niča, to je: do greha, in nisem vedel, ker me ni bilo tam, ko me je moj prvi prednik požrl z zelo grenkim ugrizom (5 Mz 32.24). Odtod prihaja to, da se $\mathrm{s}$ strtim srcem in telesom vdajam nasladam in grenkobam, nosim prirojeno krivdo, podedovano kazen, povsem sem oslabel in brez moči. On pa, ki je vedno isti (Ps 101.28), ki pravi: Jaz sem, ki sem (2 Mz 3.14), v resnici je, kajti njegovo bistvo je, da je, kar je.

3. Kaj je torej skupnega, kakšno je soglasje (2 Kor 6.14-15) med tistim, ki ga ni, in tistim, ki je? Kako se moreta povezati tako različni zadevi? Jaz, pravi svetnik, sem srečen v božji bližini (Ps 72.28). Neposredno se z njim ne moremo povezati, morda pa se bo mogla ta povezava uresničiti po kakem sredništvu.

In da vas ne bom še dlje zadrževal v negotovosti: obstajajo tri vezi, ki nas pritrjujejo nanj, samo te tri vezi so in samo s temi ali z njim podobnimi je povezano vse, kar je povezano. Kot prvo vez vzemite vrvi, kot drugo vez lesene ali železne žeblje, kot tretjo vez lepilo. ${ }^{6}$

Prva priveže trdno in močno, druga trdneje in močneje, tretja blago in varno.

Z vrvjo je nekako privezan na Odrešenika tisti, ki usmeri svoj pogled na čast in si prikliče v spomin obljubo, kadar ga muči vse preveč huda skušnjava; in te vrvi se nekaj časa oklepa, da ne bi svojega življenjskega vodila popolnoma prelomil. Ta vez je zagotovo trda in nadležna, pa tudi neizmerno nevarna in ne bi mogla zdržati dolgo. Ker namreč vrvi preperijo, tudi na vez, ki je čut za osebno čast, ali pozabimo ali pa jo hitro prelomimo.

So tudi ljudje, ki jih na Gospoda veličastva pritrjuje žebelj, veže jih strah Gospodov. Takega človeka ne plaši obličje ljudi, ampak misel na strahote pekla. Ne boji se, da bi grešil, ampak da bi gorel. Ta vez je močneje in trdneje vtisnjena vanj kakor prva vez, kajti medtem ko oni omahuje glede življenjskega vodila, ta življenjskega vodila ne opusti.

Tretji pa je prilepljen nanj z lepilom, to je z ljubeznijo. Njegova vez je prav tako blaga kakor varna, kajti tisti, ki se druži $z$ Gospodom, je $z$ njim en duh (1 Kor 6.17). Ta je tisti, ki vse, karkoli in kjerkoli že dela ali se mu dogaja, usmeri in obrne v svoj prid. Srečen je takšen človek, njegov duh je prepoln vzvišene veličine. Poln blaženosti in maziljenja nosi vse in vsi nosijo njega.

5 Sv. Avguštin pravi: „Bog je povsod navzoč ... Kako pomilovanja vredno je, da smo daleč od njega, ki je povsod." (Enarr. in Ps 99.5)

6 Te tri metafore najdemo že pri Platonu, pri katerem so ločene (vezi in lepilo na eni strani, žebelj na drugi strani), povezane pa so pri Porfiriju, pri Gregorju iz Nise, pri Ambrožu in pri Avguštinu. Pri omenjenih avtorjih vse tri vezi pomenijo odvisnost duše od telesa in od njegovih nagnjenj, pri Bernardu pa se pomen spremeni: pomenijo združitev duše z Bogom. 
Zavestno razžaliti obličje Vsemogočnega, čeprav v najmanjši zadevi, se mu zdi strašneje in grozoviteje od samega pekla. To je ljubitelj bratov, ki veliko moli za ljudstvo in za sveto mesto Jeruzalem. (2 Mkb 15.14). Lepilo je dobro (Iz 41.7), pravi Izaija. V resnici je dobro in prijetno (prim. Ps 132.1), kajti drugi dve vezi sta v primerjavi s to, - če že ne slabi -, pa vsaj težki in neznosni (Mt 23.4).

4. Toda tisto usmiljeno oko, ki dobro ve, kako smo narejeni (Ps 102.14), nikogar od teh, ki morajo biti rešeni, ne pusti pri prvi vezi, ampak jih privede do druge. Pa tudi tam jih ne zapusti, ampak jih od druge vezi popelje k tretji.

Pri prvi vezi v potu svojega obraza komaj zdržimo kako uro, in to zato, ker nas je sram, da bi popustili. Pri drugi v strahu in upanju že napredujemo. Pri tretji v ljubezni dosežemo popolnost. Ko torej tako izključimo prvi dve vezi, strah in sram hkrati, počivamo na naslonjalu (prim. Vp 3.10; 1.12) ljubezni same.

Tako je bil tudi Kristus najprej zvezan, nato pribit na križ, potem pa je bil pri maziljenju premazan $\mathrm{z}$ dišavnim lepilom. Ne zato, ker bi bilo s takšnimi dišavami treba ohraniti njegovo telo (prim. Jn 19.40), ki nikakor ni moglo razpasti (prim. Flp 1.23) ali gledati trohnobe (Apd 2.27), ampak ker on, ki je zaradi nas prenesel pljunke Judov (prim. Mt 26.67), prav tako zaradi nas ni imel za nedostojno, sprejeti mazilo vernih (prim. Jn 12.7-8; Jn 19.40). In bodi pozoren na to, da je bil en sam dan zvezan z vrvmi in pribit z žeblji, in že je po maziljenju kot zmagovalec vstal in bo zmagoval in živel vekomaj.

Tako tudi svojih izvoljenih ne pusti predolgo v prej omenjenih dveh vezeh, ampak izlije nanje maziljenje svojega usmiljenja, da bi križani svetu, svet $p a$ njim (Gal 6.14), vstali v novosti duha (Rim 7.6) in rekli: Kdo nas bo ločil od Kristusove ljubezni? (Rim 8.35).

5. S tem lepilom nas je prilepil nase oni božji pogled, in to še pred stvarjenjem sveta, da bi bili sveti in brezmadežni pred njegovim obličjem v ljubezni (Ef 1.4).

Vemo namreč, da nihče, ki je rojen iz Boga, ne greši, ampak ga iz Boga rojeni varuje (1 Jn 5.18). Iz Boga rojeni je večna in vnaprejšnja izvolitev, s katero nas je Bog vnaprej določil, naj bomo skladni s podobo njegovega Sina (Rim 8.29). Nobeden od teh ne greši (1 Jn 3.6), to pomeni: ne vztraja v grehu, ker Gospod pozna tiste, ki so njegovi (2 Tim 2.19), in božji načrt ostaja nepreklicen (prim. Rim 9.11; Heb 6.17-18; 12.27).

Čeprav Davida žge in zaznamuje pečat srahotnih zločinov (prim. 2 Sam 11.1-12.23), čeprav je Marija Magdalena obsedena od sedmih hudih duhov (prim. Lk 8.2), čeprav se prvak apostolov pogrezne v brezno zatajitve (prim. Mt 26, 69-75), jih vendarle nihče ne more iz božje roke oteti ( $2 \mathrm{Mz} 32.39$ ). Tiste, ki jih je vnaprej določil, je tudi poklical; in tiste, ki jih je poklical, je tudi opravičil (Rim 8.30). Ali nismo srečni v njegovi bližini (Ps 72.28)?7

7 David, Marija Magdalena in Peter so kljub velikim grehom iskali Boga in ga našli. Govor je o vnaprejšnji določenosti in izvoljenosti: tisti, ki jih je Bog pritrdil nase s to vezjo, se pravi, tako da ga trajno, zaupljivo in ljubeče iščejo, se z lahkoto spreobrnejo. 
Iščite, bratje, iščite Gospoda in njegovo mogočnost, vedno iščite njegovo obličje (Ps 104.4). Naj oživi srce vseh vas, ki Boga iščete (Ps 68.33). Moja duša, pravi, bo njemu živela (Ps 21.31), duša, ki je mrtva za ta svet. Tista duša namreč, ki živi za svet, ne živi zanj.

Iščimo ga torej tako, da ga bomo vedno iskali in da bo rekel o nas, ko nas bo prišel iskat: To je rod tistih, ki ga iščejo, ki hočejo najti tvoje obličje, Bog Jakobov (Ps 23.6). Zatorej se dvignite, starodavne duri, da vstopi kralj veličastva (Ps 23.7) in mi z njim, ki je Bog, slavljen na veke (Rim 9.5). 


\section{KAKO SE JE VZDIGNIL ČEZ VSA NEBESA, DA BI NAPOLNIL VSE (EF 4.10)}

Bernard je napisal šest govorov o vnebohodu, ki ga je imel posebno rad, ker je zaključek in sklep skrivnosti, ki so se zvrstile pred tem dogodkom. Vnebohod je vrnitev učlovečene Besede, Kristusa, $k$ Očetu, potem ko je s svojim zgledom in $s$ svojim poučevanjem, strpljenjem in z vstajenjem dokončal delo, ki ga je sprejel in ki bo njegov sad Sveti Duh. Za kristjane je Gospodov odhod klic: vera mora očistiti njihov razum, da mu bodo lahko dokazali svojo ljubezen, če bodo sprejeli, kar od njih zahteva božja volja.

1. Ta slovesnost, moji ljubljeni bratje, je praznik veličastva, in da tako rečem, praznik veselja. V njej se izkazuje edinstvena slava Kristusu, pa tudi nam je podeljeno izredno veselje. To je namreč dokončanje in dopolnitev vseh drugih slovesnosti, osrečujoči sklep celotne poti, ki jo je prehodil božji Sin. On, ki se je spustil, je isti, ki se je vzdignil na današnji dan čez vsa nebesa, da bi napolnil vse (Ef 4.10). Dokazal je že, da je gospodar vesoljstva, gospodar vsega, kar je na zemlji, v morju in v podzemlju, ${ }^{8}$ in treba je bilo le še, da se $s$ podobnimi dokazi - ali celo močnejšimi - izkaže za gospodarja vsega ozračja in nebes.

Zemlja ga je namreč prepoznala kot Gospoda, ker je na njegov mogočni klic, ko je zavpil z močnim glasom: »Lazar, pridi ven!« (Jn 11.43), vrnila umrlega. Prepoznalo ga je morje, ker je postalo trdno pod njegovimi nogami, in apostoli so mislili, da vidijo prikazen (prim. Mt 14.26). Prepoznalo ga je podzemlje, ki je razbil njegova bronasta vrata in presekal železne zapahe (prim. Ps 106.16); tam je tudi zvezal onega nenasitnega klavca ljudi, ki se imenuje hudič in Satan (prim. Raz 20.2).

Prav zares, ta, ki je od mrtvih obudil umrle, gobave očistil, slepim vrnil vid, hromim utrdil kolena in odpihnil vse bolezni, ta je bil gospodar vsega in $\mathrm{z}$ isto roko, s katero je vse naredil, je tudi prenovil, kar je propadlo.

Tako je tudi zanj, ki je vnaprej povedal, da bo Peter v ustih ribe našel stater (prim. Mt 17.27), brez vsakega dvoma jasno: on je gospodar morja in gospodar vsega, kar se v morju giblje.

Razorožil je zračna vladarstva in jih pribil na svoj križ (prim. Kol 2.1415) - očitno je torej, da je dobil oblast nad peklenskimi delavnicami. On je namreč tisti, ki je hodil iz kraja $v$ kraj ter delal dobra dela in ozdravljal vse, ki so bili pod hudičevo oblastjo (Apd 10.38), ki se je ustavil na ravnem kraju, da bi učil množice (prim. Lk 6.17; Lk 5.3), ki je stopil pred upravitelja (prim. Mt 27.2), da bi prenašal udarce (prim. Jn 18.22), ki je v vsem času, odkar se je prikazal na zemlji in se družil z ljudmi (prim. Bar 3.38), prestajal hude napore (prim. 2

8 Kristus je gospodar nad vsemi elementi, nad zemljo, vodo, zrakom, nebom in nad peklom; napolnjuje vse, ko sestopa, se spušča dol (descensio) in ko se vzdiguje gor (ascensio). 
Kor 11.23) in ustvarjal odrešitev sredi dežele (prim. Ps 73.12).

2. Za to, da bo dokončana, Gospod Jezus, tvoja suknja brez šiva, da bo izpopolnjena čistost naše vere, je treba samo še to, da se pred očmi učencev (prim. Apd 1.9) kot gospodar ozračja vzdigneš po sredi ozračja čez vsa nebesa (prim. Ef 4.10) ${ }^{9}$. To bo dokaz, da si Gospodar vesoljstva, ker si vse v vsem izpolnil (prim. Ef 1.23). V tvojem imenu se bo zagotovo moralo pripogniti vsako koleno $\mathrm{v}$ nebesih, na zemlji in pod zemljo in vsak jezik bo moral izpovedati, da prebivaš v slavi Boga Očeta (prim. Fil 2.10-11) in na njegovi desnici. Na tej desnici so večne radosti (prim. Ps 15.11); zato apostol opozarja, naj iščemo to, kar je zgoraj, kjer je Kristus, sedeč na božji desnici (prim. Kol 3.1), kajti tam je zagotovo naš zaklad Jezus Kristus, v katerem so skriti vsi zakladi modrosti in spoznanja ( Kol 2.3), v katerem telesno biva vsa polnost božanstva (prim. Kol 2.9).

3. Kaj mislite, bratje, kako velika bolečina in strah sta napolnila srca apostolov, ko so videli, da se je vzdignil od njih in je bil vzet v nebo (prim. Apd 1.9-11)? ${ }^{10} \mathrm{Ni}$ se povzpel po stopnicah, ni ga v nebo potegnila nobena vrv - resda so ga spremljali angeli, ki so mu stregli, a ga niso podpirali -, stopal je gor v svoji silni moči (prim. Iz 63.1). Izpolnilo se je, kar jim je napovedal: Tja, kjer sem jaz, vi ne morete priti (Jn 7.34). Po katerihkoli krajih na zemji bi hodil, povsod bi hodili za njim, ne da bi se ločili od njega. Stopili bi v morje z njim, kakor je nekoč storil Peter (prim. Mt 14.29-30), in bi se izpostavili nevarnosti, da se potopijo. Kamor je šel zdaj, pa niso mogli iti za njim (prim. Jn 13.36), kajti minljivo telo obtežuje dušo, zemeljski šotor tlači zaskrbljeni um (Mdr 9.15). Prehuda je bila torej bolečina, ko so videli, da je bil vzet izpred njihovih oči in čutov on, zaradi katerega so vse zapustili (prim. Mt 19.27). In tako svatje, ženinovi prijatelji, niso mogli drugega kakor žalovati, ker je bil ženin od njih vzet (prim. Mt 9.15). Nič manjši ni bil njihov strah, ker so bili zapuščene sirote (prim. Jn 14.18) sredi Judov, ne še odeti v moč z višave (prim. Lk 24.49).

Medtem ko jih je blagoslavljal, je bil torej vzet v nebo (prim. Lk 24.50-51) in morda globoko usmiljenje (prim. Kol 3.12) do učencev, ki jih je zapuščal $\mathrm{v}$ bedi in nebogljene, zato ni omajalo njegovega srca, ker je odhajal, da jim pripravi prostor (prim. Jn 14.2) in ker je bilo zanje bolje (prim. Jn 16.7), da jim odtegne svojo telesno navzočnost. ${ }^{11}$ Kako blažena, kako dostojanstvena je bila ta procesija, za katero še apostoli niso bili vredni hoditi, ko ga je veličastni sprevod svetih duš in nebeških moči privedel $\mathrm{k}$ Očetu in je sédel na božjo desnico (prim. Mr 16.19)! Zdaj je v resnici napolnil vse (prim. Ef 4.10), ker

9 Apostoli so zapuščeni, kot znamenje svete suknje pa jim bo podarjena nova celovitost.

10 Kakor drugi cistercijani je bil tudi Bernard velik nasprotnik razkošnih obredov in slovesnosti pri redovnikih. V Clairvaux pa je za vnebohod kljub temu vpeljal procesijo, ki so jo kmalu sprejele vse opatije njegovega reda. V govoru, ki ga je imel za svojo skupnost, je na dolgo opisal slovesni Kristusov vstop v božje kraljestvo, v tekstu, ki ga je pripravil za objavo in je pred nami, pa je redkobeseden glede teh podrobnosti, a se toliko bolj poglobi v smisel skrivnosti samega obreda procesije, to je, v Kristusovo in našo vrnitev k Očetu, v Svetem Duhu.

11 Verni so lahko potolaženi, ker bo trpljenju (descensio) sledilo poveličanje (ascensio). 
je bil rojen med ljudmi in z ljudmi se je družil (prim. Bar 3.38), od ljudi in za ljudi je trpel in umrl, vstal od mrtvih, šel v nebesa, sedi na božji desnici. Zdaj prepoznam oblačilo, od vrha scela stkano (prim. Jn 19.23), ki ga je do konca izdelalo to nebeško prebivališče, kjer je bil napolnjen in je vse napolnil Gospod Jezus Kristus.

4. Toda kaj imam jaz s temi slovesnostmi? Kdo me bo potolažil, Gospod Jezus, ker te nisem videl visečega na križu, iznakaženega zaradi udarcev, smrtno bledega, ker nisem trpel skupaj s križanim, ker nisem počastil mrtvega, ko bi vsaj s svojimi solzami rad ublažil znamenja njegovih svetih ran? Kako si me lahko zapustil brez pozdrava, ko si se, veličasten v svoji obleki (prim. Iz 63.1), Kralj veličastva (prim. Ps 23.7), vrnil v višave nebes?

Moja duša se nikakor ne bi mogla potolažiti (prim. Ps 76.3), ko me ne bi bili angeli z glasnim vriskanjem (prim. Ps 46.2; Iz 48.20) prehiteli. Govorili so: »Možje Galilejci, kaj stojite in gledate v nebo? Ta Jezus, ki je bil vzet od vas v nebo, bo prišel prav tako, kakor ste ga videli iti v nebo. (Apd 1.11) « Prav tako bo prišel," pravijo. Ali nas bo torej prišel iskat v tisti tako edinstveni in hkrati tudi vesoljni procesiji, ko se bo ob spremstvu angelov, ki bodo $\mathrm{v}$ polnem številu hodili pred njim, in vseh ljudi, ki bodo hodili za njim, spustil dol sodit žive in mrtve? Brez vsakršnega dvoma bo prišel, vendar tako, kakor se je vzdignil, ne tako, kakor se je prej spustil. Nemočen je namreč prišel najprej življenja reševat (prim. Lk 9.56), veličasten pa bo prišel to truplo obudit od mrtvih in ga bo naredil podobno telesu svojega veličastva (prim. Flp 3.21) ${ }^{12}$, tako da bo to našo posodo obdal s toliko obilnejšo častjo (prim. 1 Kor 12.23), kolikor bornejša je. In tedaj se bo prikazal z močjo in z veliko slavo (prim. Lk 21.27), on, ki je bil prej skrit v slabosti mesa (prim. Gal 4.13). Videl ga bom tudi jaz, pa ne zdaj, gledal ga bom, pa ne od blizu (prim. $4 \mathrm{Mz} 24.17$ ), in to drugo poveličanje bo zaradi vse presegajočega sijaja (prim. 2 Kor 3.10) jasno zasenčilo prvo poveličanje.

5. Medtem pa je bil vzet na Očetovo desnico in zdaj pred božjim obličjem posreduje za nas. Sedi torej na njegovi desnici (prim. Ps 109.1), v desni roki ima usmiljenje, v levi roki sodno oblast: ${ }^{13}$ najobilnejše usmiljenje in najstrožjo sodno oblast, trdno drži v desni roki vodo, v levi roki ogenj. In tako silna je njegova dobrota nad tistimi, ki se ga bojijo, kakor je nebo visoko nad zemljo (prim. Ps 102.11), da bi vsi okušali večje slapove Gospodove milosti, kakor je velika razdalja med nebom in zemljo. Božji načrt nad njimi ostane namreč nespremenljiv (prim. Rim 9.11) in Gospodova dobrota je od vekomaj, do vekomaj in na veke traja za tiste, ki se ga bojijo (prim. Ps 102.17): od vekomaj zaradi vnaprejšnje izvolitve, do vekomaj zaradi poveličanja. Prav tako ravna $\mathrm{z}$ zavrženimi; strašen je do človeških otrok (prim. Ps 65.5), na obeh straneh je

12 Od Gregorja Vélikega dalje poznamo dva Kristusova prihoda: v prvem prihodu je med ljudi prišel $\mathrm{z}$ učlovečenjem in spet bo prišel v drugem prihodu, da jih sodi ob koncu sveta. Bernard pa uvede še tretji prihod: Kristus prihaja po milosti prebivat v dušo vsakega kristjana, vendar se mora vernik na ta prihod pripraviti z očiščenjem.

13 Obstaja nekakšna vnaprejšnja določenost med pojmoma misericordia in iudicium, ne pa absolutna gotovost zveličanja. 
izrek sodbe nespremenljiv: v večnosti velja za tiste, ki so na poti odrešenja, in za tiste, ki so na poti pogubljenja (prim. 2 Kor 2.15). Kdo ve, ali so imena vseh vas, ki vas zdaj tukaj vidim, zapisana v nebesih (prim. Lk 10.20) in zabeležena v knjigi vnaprejšnje izvolitve? Zdi se mi, da vidim nekatera znamenja vaše poklicanosti in opravičenja $\mathrm{v}$ vašem prijateljevanju s ponižnostjo. Kaj misliš, kako veliko veselje bi preželo vse moje kosti, ko bi se mi posrečilo to izvedeti? Toda človek ne ve, ali je ljubezni ali sovraštva vreden (Prd 9.1).

6. Zato, preljubi, prenašajte to za vzgojo (prim. Heb 12.7), ki ste se ji prepustili, da se boste po ponižnosti povzpeli v višave, ker obstaja samo ta pot in razen te ni nobene druge poti. Tisti, ki hodi drugače, pade prej, kakor se vzpne, ker je ponižnost edina, ki dviguje, edina, ki vodi v življenje (prim. Mt 7.14). Kristus namreč, ki zaradi svoje božanske narave ni mogel niti rasti niti se vzpenjati, ker nad Bogom ni nič, je našel sredstvo, ki mu je omogočilo, da je rastel ${ }^{14}$ : spustil se je dol, prišel je, postal je človek, trpel je in umrl, da bi preprečil našo večno smrt: zato ga je Bog povzdignil (prim. Flp 2.9), vstal je od mrtvih, šel v nebesa, sedi na božji desnici. Pojdi in tudi ti tako delaj (Lk 10.37). Ne moreš se namreč povzpeti, če se prej ne spustiš (prim. Ef 4.9), kakor je določeno z večnim zakonom: Vsak, kdor se povišuje, bo ponižan, in kdor se ponižuje, bo povišan (Lk 14.11; 18.14). O, sprevrnjenost! O, zabloda Adamovih sinov! Čeprav je vzpenjati se nekaj najtežjega, spuščati se pa nekaj najlažjega, se oni lahkomiselno vzpenjajo, prav težko pa sprejmejo spuščanje. Pripravljeni so sprejeti časti in visoke cerkvene položaje, ki bi vlivali strah celo angelskim ramam. Težko pa je najti takšne, Gospod Jezus, ki bi se pustili vleči ali bi hoteli biti peljani po poti tvojih zapovedi (prim. Ps 118.32) zato, da bi hodili za teboj. ${ }^{15}$ Nekaj jih je, ki se pustijo vleči, in ti lahko rečejo: Povleci me za sabo (Vp 1.3), drugi se pustijo peljati, in ti pravijo: Kralj me je peljal v svoje sobane (Vp 1.3). Spet tretji so vzeti, kakor je bil apostol vzet do tretjega neba (prim 2 Kor 12.2). Srečni so prvi, ki si s svojo stanovitnostjo pridobivajo svoje življenje (prim. Lk 21.19), srečnejši so drugi, ker se mu s svojo pesmijo zahvaljujejo (prim. Ps 27.7), najsrečnejši so tretji, saj je moč njihove svobodne volje tako rekoč pokopana $\mathrm{v}$ najgloblje božje usmiljenje in so $\mathrm{z}$ duhom očiščenja (prim. Iz 4.4) vzeti v bogastvo njegove slave (prim. Rim 9.23; Ef 1.18). Ne vedo, ali so bili vzeti v telesu ali zunaj telesa (prim. 2 Kor 12.2), vse, kar vedo, je to, da so bili vzeti.

Srečen tisti, ki ima vsepovsod tebe za vodnika, Gospod Jezus, ne pa tistega duha odpadnika, ki se je hotel takoj in brez odloga povzpeti in ga je božja desnica udarila z vso silo. Mi pa, tvoje ljudstvo in ovce tvoje paše (prim. Ps 78.13), naj hodimo za teboj, po tebi in $\mathrm{k}$ tebi, ker ti si pot, resnica in življenje

14 "Rast Boga« je samo simbolična: Bog ne more rasti, v njem se nič ne spremeni, ko se spusti med ljudi. Stvarstvo pa prav s tem dogodkom ( $\mathrm{z}$ učlovečenjem Boga) stopi v popolnoma nov odnos z Bogom.

15 Hoja za Kristusom, descensio in ascensio - v potrpljenju in v vzpenjanju -, je pomembnejša od vseh drugih prizadevanj. 
(prim. Jn 14.6): pot v svojem zgledu, resnica v svojih obljubah, življenje v svojem plačilu. Besede večnega življenja imaš in verujemo in vemo (prim. Jn 6.69), da si ti Kristus, sin živega Boga, ti si Bog, ki je nad vsem, slavljen na veke vekov (prim. Rim 9.5). 